\section{BA address: Huxley responds}

Sir Andrew Huxley, Royal Society Research Professor in the Department of Physiology at University College London, responds to Nature's editorial on the presidential address he delivered to the recent British Association meeting

SiR,-Your editorial (8 September) about my presidential address to the British Association misses the point of what I said on the relations between human values and scientific research. I discussed this matter in several contextsevolution; paranormal phenomena; the Lysenko controversy; and the inheritance of human ability. You mention only the last, and you write as though I had simply called for more research in this field. You have misread me. What I was urging was that the conclusions of whatever research is done should not be biased by preconceptions or by external pressures. In recent years, this issue has been bedevilled by strong pressures, which in Europe and in most of the USA have come almost exclusively from those who insist that the genetic component is negligibly small. These pressures have taken forms which I hope you agree are improper-the baseless insinuation that there is necessarily something 'racist' in admitting the possibility of a genetic component; denial of freedom of speech; and physical attacks. It is easy to imagine similar pressures being exerted by others in the opposite direction; if this occurs I shall resist them just as forcibly, but as far as I know this has not been happening, at least in Europe, since the defeat of Hitler.

I did not say much about the good that might come from an increase of knowledge on the causes of differences in ability, partly because this was not the subject of my address, partly because I am no expert in these matters but also because I did not wish to buy off opposition to my main thesis by playing down the risk of uncomfortable passages ahead if, in any field, we allow evidence to be collected and published. In my view the independence of Science is something that should be accepted irrespective of the consequences that may appear to us to be likely. Human affairs are so unpredictable that it is more probable that good will be done by letting our beliefs follow from the evidence, than by deciding without the evidence what beliefs will lead to the best actions. Since you challenge me, however. I will set out some of the ways in which increased knowledge could do gond.

You say "Questions are bound to be asked about motives for doing more research, especially as there is little doubt that inheritance does play at least some and maybe a very significant part in the acquisition of ability". One answeralready given in my address-is as follows. If inheritance plays no significant part, long-term policy need only aim to provide equal opportunity and to eliminate prejudice based on class and race. But if its role is "very significant", we must also build into our system compensatory advantages for groups who would otherwise feel excluded from a fair share of well-rewarded and respected occupations: 'affirmative action' as in the USA would be a step in this direction but other measures might be needed as well-perhaps for example up-grading those jobs which have the lowest requirements in scholastic attainment. Such policies would naturally be resented by the groups whom they do not favour (witness the case of Allan Bakke now before the US Supreme Court) and probably ought not to be vigorously implemented unless it is clear that a substantial genetic

\section{component exists.}

A second way in which further investigation could be valuable is the following: if there are no appreciable genetic differences, the best way to establish the fact will be to carry out genetic investigations. An example is that Shockley's approaches to the National Academy of Sciences in the United States led indirectly to a review of the position being undertaken under the auspices of a committee of the US Social Science Research Council, and the resulting book (J. C. Loehlin, G. Lindzey \& J. N. Spuhler, Race differences in intelligence, W. H. Freeman \& Co., 1975) gives prominence to two interesting genetic investigations, one based on correlation of IQ with blood groups in persons of mixed ancestry, and the other on the performance of illegitimate offspring of Negro and White US servicemen with German women during the occupation of Germany after World War II. Neither of these gave any support for a simple genetic difference between Negro and White.

Yet another reason to wish for greater knowledge is that, as understanding improves, so emotional reactions will become less. Suppose, for example, that a gene were indentified which, like the sickle-cell gene, confers some resistance against a tropical disease but whose compensatory disadvantage in the homozygote is a moderate drop in scholastic ability instead of a haemolytic disease: I believe this would be regarded purely as a piece of misfortune to those affected and in no way as a matter for shame.

It would be idle to suggest more specifically the way in which improved knowledge and understanding might be valuable. The chief characteristic of research is that its outcome is not known in advance. A large part of my address was devoted to examples where the progress of science was held up by a false assumption that a result could be deduced by extrapolation from what was already known. This part of my address you dismiss as "a lengthy aside", but it is highly relevant to the question of the causation of differences of ability. Our understanding in this field is still in a primitive state, and I would guess that there will be several unforeseen changes of view on both the environmental and the genetic side before an agreed position is reached. Meanwhile, what is needed is, on the one hand, for policy-makers to be conscious of this uncertainty, to be guided largely by humane considerations and by common sense rather than by predictions based on particular theories, and to avoid decisions liable to be harmful if unsuspected factors turn out to be at work. On the other hand, research should continue, with as little bias as can be attained and without premature claims on either side to have reached a final solution.

I retain a conviction-difficult no doubt to justify rigorously in each individual case-that an improvement in our understanding of a problem will in the long run improve our attempts to solve it. I find it deeply depressing that you, the Editor of the leading general scientific journal of the whole world, should in your final sentences tell us in effect that, in any field which is important enough to generate emotion, we ought not to undertake research until we are sure that its conclusion will be to our liking.

\section{ANDrew HuXley, FRS}

The full text of Sir Andrew Huxley's address appeared in The Times Higher Education Supplement of 2 September 